\title{
Novel Mannitol-Based Small Molecules for Inhibiting Aggregation of $\alpha$-Synuclein Amyloids in Parkinson's Disease
}

\section{OPEN ACCESS}

Edited by:

Matthias Peter Mayer,

Universität Heidelberg, Germany

Reviewed by:

Leonid Breydo,

St. Jude Children's Research Hospital,

United States

Martin M. Muschol, University of South Florida,

United States

*Correspondence: Daniel Segal

dsega/@post.tau.ac.il

Specialty section:

This article was submitted to

Protein Folding, Misfolding and

Degradation,

a section of the journal

Frontiers in Molecular Biosciences

Received: 12 December 2018 Accepted: 01 March 2019

Published: 22 March 2019

Citation:

Paul A, Zhang B-D, Mohapatra $S$,

Li G, Li Y-M, Gazit E and Segal D (2019) Novel Mannitol-Based Small Molecules for Inhibiting Aggregation of $\alpha$-Synuclein Amyloids in Parkinson's

Disease. Front. Mol. Biosci. 6:16.

doi: 10.3389/fmolb.2019.00016

\author{
Ashim Paul ${ }^{1}$, Bo-Dou Zhang ${ }^{2}$, Satabdee Mohapatra ${ }^{1}$, Gao Li ${ }^{2}$, Yan-Mei Li ${ }^{2,3,4}$, Ehud Gazit ${ }^{1}$ \\ and Daniel Segal ${ }^{1,5 *}$
}

'School of Molecular Microbiology and Biotechnology, Tel Aviv University, Tel Aviv, Israel, ${ }^{2}$ Department of Chemistry, Tsinghua University, Beijing, China, ${ }^{3}$ Institute of Parkinson Disease, Beijing Institute for Brain Disorders, Beijing, China, ${ }^{4}$ Center for Synthetic and Systems Biology, Tsinghua University, Beijing, China, ${ }^{5}$ Sagol Interdisciplinary School of Neurosciences, Tel Aviv University, Tel Aviv, Israel

The aggregation of the amyloidogenic protein $\alpha$-synuclein ( $\alpha$-Syn) into toxic oligomers and mature fibrils is the major pathological hallmark of Parkinson's disease (PD). Small molecules that inhibit $\alpha$-Syn aggregation thus may be useful therapeutics for PD. Mannitol and naphthoquinone-tryptophan (NQTrp) have been shown in the past to inhibit $\alpha$-Syn aggregation by different mechanisms. Herein, we tested whether the conjugation of Mannitol and NQTrp may result in enhance efficacy toward $\alpha$-Syn. The molecules were conjugated either by a click linker or via a PEG linker. The effect of the conjugate molecules on $\alpha$-Syn aggregation in vitro was monitored using Thioflavin $T$ fluorescence assay, circular dichroism, transmission electron microscopy, and Congo red birefringence assay. One of the conjugate molecules was found to be more effective than the two parent molecules and as effective as a mixture of the two. The conjugate molecules attenuated the disruptive effect of $\alpha$-Syn on artificial membrane of Large Unilamellar Vesicles as monitored by dye leakage assay. The conjugates were found to be have low cytotoxicity and reduced toxicity of $\alpha$-Syn toward SH-SY5Y neuroblastoma cells. These novel designed entities can be attractive scaffold for the development of therapeutic agents for PD.

Keywords: $\alpha$-synuclein, Parkinson's disease, mannitol, NQTrp, aggregation, inhibitor

\section{INTRODUCTION}

Intracellular or extra cellular deposits of amyloid aggregates of certain proteins are hallmarks of various neurodegenerative diseases (Ross and Poirier, 2004; Chiti and Dobson, 2006; Treusch et al., 2009). While, the mechanism of amyloid formation remains elusive, growing evidence suggests that the process proceeds through multiple steps including protein misfolding followed by formation of toxic oligomers and protofilaments, culminating into mature fibrils (Ross and Poirier, 2004; Stefani, 2004; Chiti and Dobson, 2006; Glabe, 2006; Knowles et al., 2014). $\alpha$-synuclein ( $\alpha$-Syn) is such an amyloidogenic protein, whose toxic deposits in dopaminergic neurons in the brain, are involved in the pathogenesis of Parkinson's disease (PD) and Lewy body dementia (Spillantini et al., 1997; Conway et al., 2000; Dauer and Przedborski, 2003; Cookson, 2005; Bridi and Hirth, 2018; Ghiglieri et al., 2018). $\alpha$-Syn is an intrinsically disordered protein which acquires a broad conformational 
diversity, presumably endowing it with the ability to play multiple functions (Mizuno et al., 2012; Wang et al., 2016). Yet, the exact role of $\alpha$-Syn at physiological and pathological conditions is not fully understood (Bendor et al., 2013; Ghosh et al., 2015; Dettmer, 2018). An attractive therapeutic strategy toward synucleopathies would be to reduce formation of toxic oligomers and fibrils of $\alpha$-Syn. Various attempts have been made along these lines, including the use of $\beta$-synuclein and its fragments (Shaltiel-Karyo et al., 2010; Leitao et al., 2018; Williams et al., 2018), nanobodies (Butler et al., 2016; Iljina et al., 2017), peptides (Madine et al., 2008; Choi et al., 2011, 2018), chaperones (Dedmon et al., 2005; Zhang et al., 2011), polydopamine dendrimers (Milowska et al., 2011), molecular tweezer (Prabhudesai et al., 2012), metal chelation (Mounsey and Teismann, 2012; Finkelstein et al., 2017), and various natural and synthetic small molecules (Zhu et al., 2004; Kobayashi et al., 2006; Masuda et al., 2006; Bieschke et al., 2010; Bisaglia et al., 2010; Meng et al., 2010; Scherzer-Attali et al., 2012; Singh et al., 2013; Ardah et al., 2014; Pujols et al., 2018), yet no such therapeutic is currently available. The various agents used exhibit certain limitations, including degradation by proteases and inefficient crossing of the blood brain barrier (BBB) (Begley, 2004; Werle and Bernkop-Schnürch, 2006; Gabathuler, 2010).

We have previously demonstrated inhibition of the selfassembly of $\alpha$-Syn by Mannitol (M, Figure 1) which was found to act in vitro as a chemical chaperone stabilizing $\alpha$-Syn structure through non-specific, solvent-mediated interactions (ShaltielKaryo et al., 2013). Administration of Mannitol intraperitoneally to transgenic mice expressing human $\alpha$-Syn reduced its deposites in the brain accompanied by ameliotration of various PD pathologies (Shaltiel-Karyo et al., 2013). Notably, due to its hyperosmotic capacity, Mannitol is used clinically for disrupting the blood-brain barrier (BBB) and increasing its permeability to drugs (Suzuki et al., 1985; Pan et al., 2000). Thus a dual mechanism was suggested for the compound (Shaltiel-Karyo et al., 2013). Yet, for achieving inhibition of 90\% aggregation of $\alpha$-Syn $(100 \mu \mathrm{M})$ in vitro, a higher dose of Mannitol $(0.225 \mathrm{M})$ was required, which can be a restriction from therapeutic perspective. In a separate series of experiments, we identified a quinone based derivative, Naphthoquinone-Tryptophan (NQTrp), as a generic inhibitor of fibril formation of various amyloidogenic proteins, which ameliorated $A \beta$ - and tau-engendered symptoms in animal models (Scherzer-Attali et al., 2010; Frenkel-Pinter et al., 2016). The NQTrp molecule (N, Figure 1) was developed based on the established key role of aromatic residues in facilitating the recognition and self-assembly of the amyloid monomers and in stabilizing the resultant nano-fibrils (Gazit, 2002; ScherzerAttali et al., 2010). By interfering with $\pi-\pi$ stacking of $\alpha$ Syn self-assembly, NQTrp inhibited its aggregation even at low concentration $(2 \mathrm{mM})$, resulted in $\sim 80 \%$ inhibition of $\alpha$-Syn $(100 \mu \mathrm{M})$ aggregation (Scherzer-Attali et al., 2012). A possible limitation of NQTrp from a drug development perspective is its restricted $\mathrm{BBB}$ permeability.

We hypothesized that by covalently linking NQTrp to Mannitol, its ability to cross the BBB may be enhanced. As a first step in this direction we examined here whether the conjugation of Mannitol and NQTrp would result in synergistic effect of the two parent molecules thus improving their potential efficacy toward $\alpha$-Syn in PD. To that end we generated novel compounds in which these two small molecules are conjugated to each other either directly by click linker (Rostovtsev et al., 2002; Tornøe et al., 2002) or via a PEG linker. Using various biophysical assays, the conjugate molecules were found to delay the kinetics of $\alpha$ Syn aggregation and to reduce the extent of the fibrils formed. In addition, the conjugates were non-toxic to cells and could reduce the cytotoxicity of $\alpha$-Syn aggregates. The conjugates were more potent than either Mannitol or NQTrp or their mixture.

\section{MATERIALS AND METHODS}

Mannitol and NQTrp were purchased from Sigma-Aldrich (Rehovot, Israel). Compound MCN, M2N, and M3N (Figure 1) were synthesized by us as described below. Recombinant wild type $\alpha$-Syn was purchased from rPeptide, USA (Catalog \# S-1001-2). All lipids were purchased from Avanti ${ }^{\circledR}$ Polar Lipids (USA). Unless otherwise stated, all chemicals were obtained from Sigma-Aldrich (Rehovot, Israel and Innochem, Aladdin), and were of analytical grade.

\section{SYNTHESIS OF THE MANNITOL-NQTRP CONJUGATE MOLECULES (MCN, M2N, AND M3N)}

\section{Synthesis of Compound MCN}

The stepwise chemical synthesis of the compound MCN (Figure 1) is shown in Scheme S1.

For the synthesis of compound $\mathbf{M C N}$, first compound 2 (Scheme S1) was prepared using the following protocol. 2Propynylamine (38 mg, $0.417 \mathrm{mmol}$ ) was dissolved in $1 \mathrm{~mL}$ THF/DCM (7/3) solvent. Then, EDC•HCl (79.7 mg, $0.4 \mathrm{mmol})$, HOBt $(41 \mathrm{mg}, 0.3 \mathrm{mmol})$, and DIEA $(200 \mu \mathrm{L})$ were added into the solution followed by dropwise addition of $100 \mathrm{mg}(0.28$ mmol) compound 1 (Scheme S1) dissolved in $100 \mu \mathrm{L}$ THF. After $12 \mathrm{~h}$, the solution was dried under $\mathrm{N}_{2}$ and the compound 2 (Scheme S1) was purified by column chromatography (cyclohexane/ethyl acetate $=4 / 1$ ) with yield of $91 \%$. Compound 2 was characterized by mass spectrometry (Figure S1).

Next, compound 6 (Scheme S1) was synthesized as follows. D-Mannitol (10 g, $54 \mathrm{mmol}$ ) and $100 \mathrm{mg}$ DMAP (4-dimethylaminopyridine) were dissolved in $80 \mathrm{~mL}$ pyridine. Then, 4-toluene sulfonyl chloride ( $\mathrm{TsCl}, 7.8 \mathrm{~g}, 41 \mathrm{mmol}$ ) in $80 \mathrm{~mL}$ pyridine was added dropwise into $\mathrm{D}$-mannitol solution at $0^{\circ} \mathrm{C}$ with stirring. After $24 \mathrm{~h}, 62 \mathrm{~mL}$ of $\mathrm{Ac}_{2} \mathrm{O}$ were added dropwise into the above solution at $0^{\circ} \mathrm{C}$. After additional $24 \mathrm{~h}$, the reaction was quenched with water and the crude organic product was collected after acid-base wash. The crude product was resolved by column chromatography (cyclohexane/ethyl acetate $=4 / 1)$ to obtain compound 5 (Scheme S1), which further reacted with $\mathrm{NaN}_{3}$ in $\mathrm{DMF}$ at $80^{\circ} \mathrm{C}$ for $24 \mathrm{~h}$ to obtain compound 6. The product was separated by column chromatography (cyclohexane/ethyl acetate $=9 / 1$ ) to obtain compound 6 . Then, compound $6(0.151 \mathrm{mmol})$ in $0.15 \mathrm{~mL} \mathrm{H} \mathrm{H}_{2} \mathrm{O} / \mathrm{CH}_{3} \mathrm{CN}(2 / 1)$ and compound $2(0.125 \mathrm{mmol})$ in $0.5 \mathrm{~mL} \mathrm{H}_{2} \mathrm{O} / \mathrm{CH}_{3} \mathrm{CN} / \mathrm{THF}(1 / 2 / 3)$ 


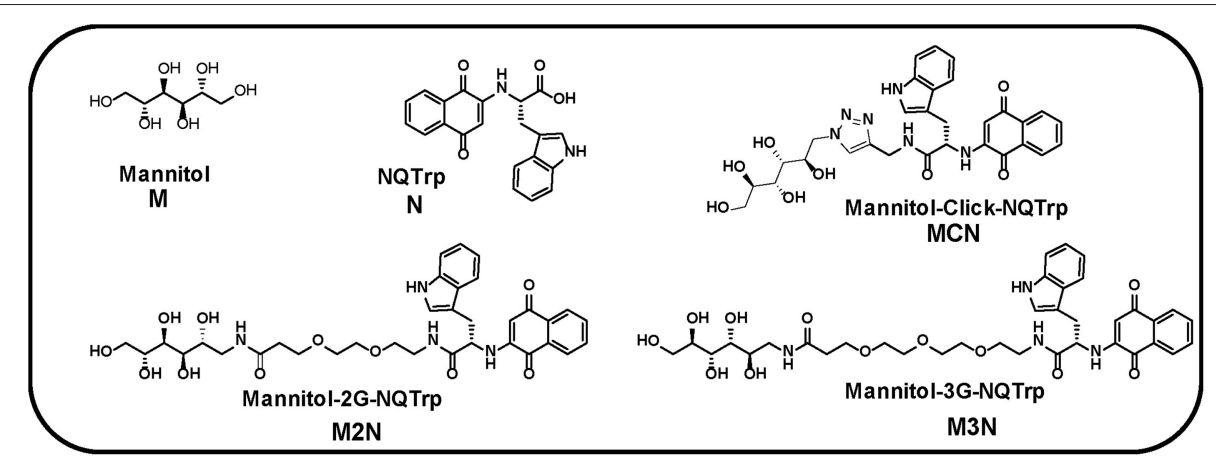

FIGURE 1 | Chemical structures of Mannitol (M), NQTrp (N), and their derivative three conjugate molecules (MCN, M2N, and $\mathbf{M} 3 \mathbf{N})$. 2G and 3G indicate two and three PEG, respectively.

were mixed in presence of sodium ascorbate $(0.126 \mathrm{mmol})$ in $0.1 \mathrm{~mL} \mathrm{H}_{2} \mathrm{O}$ and $\mathrm{CuSO}_{4}(0.0126 \mathrm{mmol})$ in $0.05 \mathrm{~mL} \mathrm{H} \mathrm{H}_{2} \mathrm{O}$, for $12 \mathrm{~h}$. Then, the mixture was purified by semi-preparative HPLC using C18 column with linear gradients of $40 \%$ to $90 \%$ of solution $\mathrm{B}\left(80 \% \mathrm{CH}_{3} \mathrm{CN} / \mathrm{H}_{2} \mathrm{O}\right.$ with $\left.0.06 \% \mathrm{TFA}\right)$ in solution $\mathrm{A}\left(\mathrm{H}_{2} \mathrm{O}\right.$ with $\left.0.06 \% \mathrm{TFA}\right)$ for $30 \mathrm{~min}(\lambda=215 \mathrm{~nm})$. After lyophilization, $43.3 \mathrm{mg}$ of compound 7 (Scheme S1) was obtained with yield of $42 \%$. Compound 7 was characterized by mass spectrometry (Figure S2).

For synthesis of compound $\mathrm{MCN}, 13.3 \mathrm{mg}$ of compound 7 (Scheme S1) were dissolved in $3 \mathrm{~mL} \mathrm{CH} \mathrm{CH}_{3} \mathrm{OH} . \mathrm{CH}_{3} \mathrm{ONa}$ was used to adjust the $\mathrm{pH}$ of solution to $\sim 8.5$. After $19 \mathrm{~h}$, the reaction was neutralized with $\mathrm{AcOH}$ and the solvent was removed under vacuum. The product was dissolved in $6 \mathrm{ml}$ $\mathrm{CH}_{3} \mathrm{CN}$ and purified with semi-preparative HPLC using $\mathrm{C} 18$ column with linear gradients of $30 \%$ to $80 \%$ of solution $\mathrm{B}(80 \%$ $\mathrm{CH}_{3} \mathrm{CN} / \mathrm{H}_{2} \mathrm{O}$ with $0.06 \%$ TFA) in solution $\mathrm{A}\left(\mathrm{H}_{2} \mathrm{O}\right.$ with $0.06 \%$ TFA) for $30 \mathrm{~min}(\lambda=215 \mathrm{~nm})$. After lyophilization, $8 \mathrm{mg}$ of compound MCN was obtained with yield of $82 \%$. The purified compound was further characterized by HPLC (Figure S3) and mass spectrometry (Figure S4).

\section{Synthesis of Compounds M2N and M3N}

The stepwise chemical synthesis of the compounds M2N and M3N is shown in Scheme S2.

A solution of 1-Amino-1-deoxy-D-mannitol (Peterson et al., 2011) (1.60 mmol) in DMSO (1 mL) was added drop wise to a solution of DIEA (6.40 mmol), linker (1.92 mmol), HOBT (2.40 $\mathrm{mmol})$, and EDC- $\mathrm{HCl}(2.40 \mathrm{mmol})$ in $4 \mathrm{~mL} \mathrm{DMSO}$ at $0^{\circ} \mathrm{C}$ for $10 \mathrm{~min}$. The mixture was stirred at room temperature for $12 \mathrm{~h}$ and $40 \mathrm{~mL}$ water were added and washed with $\mathrm{CH}_{2} \mathrm{Cl}_{2}(4 \times$ $20 \mathrm{~mL}$ ). The water layer was lyophilized to obtain a white powder. The white powder was added to $3 \mathrm{~mL} 20 \%$ piperidine/DMSO solution and was stirred for $1 \mathrm{~h}$ at room temperature. The reaction mixture was dropped into $40 \mathrm{~mL}$ of cold ether to obtain light yellow precipitate of linker-saccharide conjugate, which was dried under vacuum. Next, NQTrp $(0.138 \mathrm{mmol})$ (ShresthaDawadi et al., 1996), DIEA (0.552 mmol), HOBT (0.207 mmol), and EDC-HCl $(0.207 \mathrm{mmol})$ were dissolved in $3 \mathrm{~mL}$ DMSO and kept at $0^{\circ} \mathrm{C}$. After $10 \mathrm{~min}$, the reaction mixture was added to linker-saccharide conjugate solution $(0.138 \mathrm{mmol})$ in $1 \mathrm{~mL}$ DMSO, and the mixture was stirred at room temperature for $12 \mathrm{~h}$. The mixture was dropped into $40 \mathrm{~mL}$ of cold ether to obtain orange precipitate, which was dissolved in $2 \mathrm{~mL} \mathrm{CH}_{2} \mathrm{Cl}_{2}$ and purified by flash column chromatography to obtain the final compound M2N/M3N. Compound M2N ( $n=2$, Scheme S2) and M3N ( $n=3$, Scheme S2) were further characterized by HPLC and mass spectrometry (Figures S5-S8).

\section{Liquid Chromatography}

Purity of the compounds (MCN, M2N, and M3N) was confirmed by Waters UPLC-MS system (ESI). Solvents used: solvent A $\left(0.1 \%\right.$ formic acid in $\left.\mathrm{H}_{2} \mathrm{O}\right)$ and solvent $\mathrm{B}(0.1 \%$ formic acid in $\left.\mathrm{CH}_{3} \mathrm{CN}\right)$ on $\mathrm{C} 18$ ultra analytical column with a flow rate of $0.5 \mathrm{~mL} / \mathrm{min}$. Dual wavelength were selected at 220 and $280 \mathrm{~nm}$. Linear gradient of $5-95 \% \mathrm{CH}_{3} \mathrm{CN}$ was used in a total run time of $10 \mathrm{~min}$.

\section{Mass Spectrometry}

Masses of the purified samples were analyzed on Waters UPLC-MS (ESI + ve mode) Micromass Q-TOF equipped with Masslynx software.

\section{Stock Preparation}

$\alpha$-Syn was monomerized by a 10 min pretreatment with HFIP and the solvent was evaporated using a Speed Vac. The resulting thin film was dissolved in phosphate buffer saline (PBS) and sonicated for $5 \mathrm{~min}$. The working buffer system for all assays was PBS (100 mM, pH 7.4). Concentration of the protein was determined using Nano drop (calculated according to $\varepsilon_{280}$ of $1490 \mathrm{M}^{-1} \mathrm{~cm}^{-1}$ ) and adjusted to $50 \mu \mathrm{M}$ concentration as a stock solution. Stock solutions of Thioflavin T (ThT, $4 \mathrm{mM}$ ) was prepared in $100 \mathrm{mM}$ PBS. Stock solution hybrid molecules $(10 \mathrm{mM})$ were prepared separately in DMSO and diluted with PBS before use.

\section{Thioflavin T Assay}

For monitoring aggregation kinetics of $\alpha$-Syn, the stock solutions were diluted in $100 \mu \mathrm{L}$ wells in a 96-well black plate so that the final mixture contained $10 \mu \mathrm{M}$ of the protein and $20 \mu \mathrm{M}$ ThT in $100 \mathrm{mM}$ PBS. The inhibitor molecules (at 5:1, 1:1, 1:5 ratio of 
$\alpha$-Syn:inhibitor molecule) were added separately to designated wells and kinetics of $\alpha$-Syn aggregation was monitored by ThT fluorescence at $37^{\circ} \mathrm{C}$ with continuous shaking. The data were collected (in triplicate manner) using Infinite M200 microplate reader (Tecan, Switzerland), with measurements taken at $15 \mathrm{~min}$ intervals for $50 \mathrm{~h}$. Excitation and emission wavelengths of ThT were 440 and $485 \mathrm{~nm}$, respectively.

\section{Circular Dichroism Spectroscopy}

To analyze the secondary structure of the inhibited $\alpha$-Syn, 300 $\mu \mathrm{L}$ of the samples were taken in a cuvette (path length $1 \mathrm{~mm}$ ) and CD spectra were then recorded on a Chirascan spectrometer between the range of $190-260 \mathrm{~nm}$, and the background was subtracted from the CD spectra. Since, DMSO absorbs at far UV range, stocks of hybrid molecules were prepared in methanol for this assay.

\section{Transmission Electron Microscopy}

Samples $(10 \mu \mathrm{L})$ were placed for $2 \mathrm{~min}$ on 400 -mesh copper grids covered with carbon-stabilized Formvar film (Electron Microscopy Sciences, Hatfield, PA). Excess fluid was removed, and the grids were negatively stained with $2 \%$ uranyl acetate solution $(10 \mu \mathrm{L})$ for $2 \mathrm{~min}$. Then, the excess fluid was removed and allowed to dry for $5 \mathrm{~min}$. The samples were viewed using a JEM-1400 TEM (JEOL), operated at $80 \mathrm{kV}$.

\section{Congo Red Birefringence}

Congo red powder was dissolved in $80 \%$ aqueous ethanol to prepare a saturated stock solution. The aggregated $\alpha$-Syn solution $(5 \mu \mathrm{L})$ in the absence or presence of different doses of the inhibitors were mixed with $5 \mu \mathrm{L}$ of saturated Congo red solution. The suspension was drop casted over a glass side and the samples were dried in air and kept in a desiccator before birefringence analysis. The samples were viewed at 20X magnification with a Nikon Eclipse TI polarizing microscope. Digitized images were obtained using a Nikon DS Ril digital camera.

\section{Large Unilamellar Vesicles (LUVs) Preparation and Carboxyfluorescein Entrapment}

The vesicles were prepared according to the reported protocol (Zhu et al., 2003; Williams et al., 2010). Briefly, the LUVs were prepared using three different lipids, DMPC, Cholesterol, and GM1 at 68:30:2 molar ratios and were solubilized to make $2 \mathrm{mM}$ stock solution in chloroform and methanol (2:1) and the solvents were evaporated to make lipid films using nitrogen gas. The resulting lipid film was hydrated in $50 \mathrm{mM}$ potassium phosphate buffer, pH 7.4 containing $5 \mathrm{mM}$ carboxyfluorescein dyes. Then, the solution was vortexed vigorously for $30 \mathrm{~min}$ to emulsify the lipid mixtures. Next, the glass vial containing the lipid emulsion was dipped into liquid nitrogen for instant cooling and after $5 \mathrm{~min}$ the frozen solution was dipped into water bath at $50-60^{\circ} \mathrm{C}$ for thawing (Traikia et al., 2000). This step was repeated five times. Excess dye was removed by ultracentrifugation, the supernatant dye solution was discarded, and the lipid pellet was re-hydrated with $50 \mathrm{mM}$ potassium phosphate buffer. This step was repeated 2 more times and the final lipid pellet was collected followed by addition of $500 \mu \mathrm{L}$ of potassium phosphate buffer and vortexed to obtain homogenous suspension of $2 \mathrm{mM}$ of dye loaded LUVs. The dye leakage study was performed in triplicate on Infinite M200 microplate reader (Tecan, Switzerland). Excitation and emission wavelengths of carboxyfluorescein were 490 and $517 \mathrm{~nm}$, respectively.

\section{Cell Cytotoxicity}

The SH-SY5Y cell line $\left(2 \times 10^{5}\right.$ cells $\left./ \mathrm{mL}\right)$ was cultured in 96-well tissue microplates $(100 \mu \mathrm{L} /$ well $)$ and allowed to adhere overnight at $37^{\circ} \mathrm{C}$. The inhibitor molecules were dissolved in DMEM:Nutrient mixture F12 (Ham's) (1:1) (Biological Industries, Israel) at different concentrations (1, 5, 10, 20, 50 , and $100 \mu \mathrm{M})$. The negative control, represented by zero, was prepared as medium without any hybrid molecules and treated in the same manner. $100 \mu \mathrm{L}$ of medium with or without the inhibitor molecules were added to each well. Following incubation for $24 \mathrm{~h}$ at $37^{\circ} \mathrm{C}$, cell viability was evaluated using the 2,3-bis(2-methoxy-4-nitro-5-sulfophenyl)2H-tetrazolium-5-carboxanilide (XTT) cell proliferation assay kit (Biological Industries, Israel) according to the manufacturer's instructions. Briefly, $100 \mu \mathrm{L}$ of the activation reagent was added to $5 \mathrm{~mL}$ of the XTT reagent, followed by the addition of $50 \mu \mathrm{L}$ of activated-XTT solution to each well. After $2 \mathrm{~h}$ of incubation at $37^{\circ} \mathrm{C}$, color intensity was measured using an ELISA microplate reader at 450 and $630 \mathrm{~nm}$. Results are presented as mean and the standard error of the mean. Each experiment was repeated at least three times.

\section{RESULTS AND DISCUSSIONS}

Three conjugate molecules composed of Mannitol (M) chemically linked to NQTrp (N) were synthesized, either by click chemistry or via a PEG linker, termed as hybrid MannitolClick-NQTrp (MCN, Figure 1), Mannitol-2G-NQTrp (M2N, Figure 1), and Mannitol-3G-NQTrp (M3N, Figure 1: where $2 / 2 \mathrm{G}$ and $3 / 3 \mathrm{G}$ indicate two and three PEG unit, respectively). For details of the synthesis see Materials and Method section. We hypothesized that the chemical linkage (click or PEG) would not affect the individual activity of Mannitol or NQTrp or would have a negligible effect. The PEG linkers in hybrid molecules (M2N and M3N) were used to enhance the flexibility and biocompatibility (Harris and Chess, 2003).

\section{Kinetics of Inhibition of $\alpha$-Syn Aggregation}

Mannitol only and NQTrp only (hereafter termed $\mathbf{M}, \mathbf{N}$, respectively) and an equimolar mixture of them $(\mathbf{M}+\mathbf{N})$ were used as reference. The aggregation kinetics of $\alpha$-Syn in absence or presence of the different inhibitors was monitored by ThT fluorescence assay. ThT is an amyloid binding dye which fluoresces upon binding to the cross- $\beta$ sheet structure of the amyloid fibrils. Its level of fluorescence is commonly used to monitor the amount of fibrils present in the solution (LeVine, 1999). $\alpha$-Syn was dissolved in PBS buffer ( $\mathrm{pH} 7.4,100 \mathrm{mM}$ ) to obtained a final working concentration of $10 \mu \mathrm{M}$ and was 

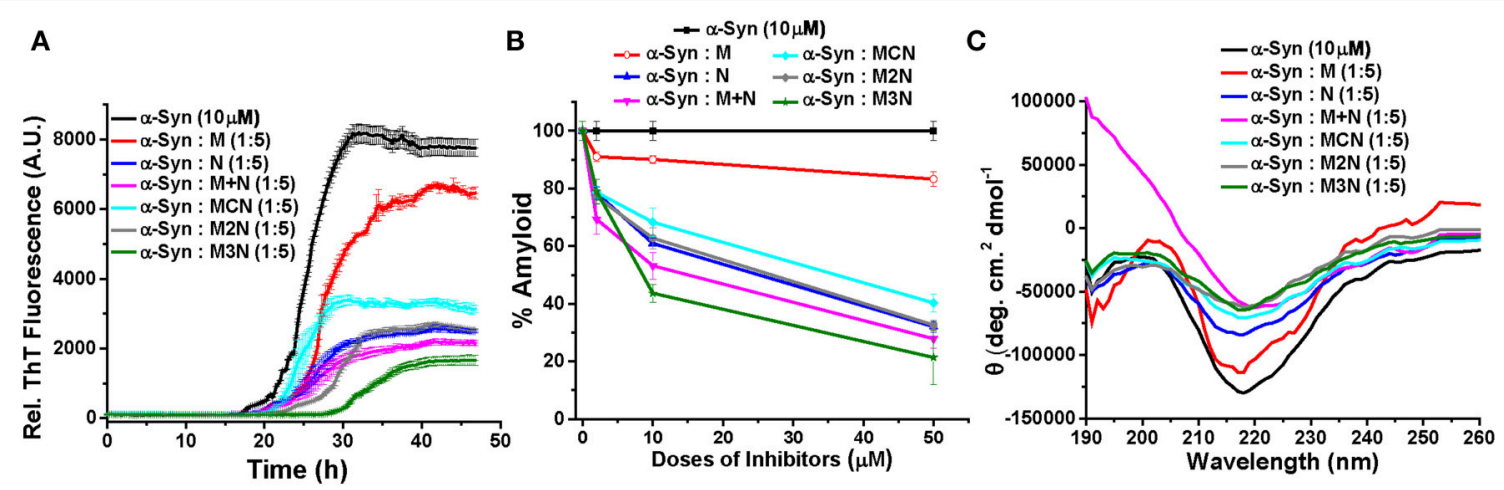

FIGURE 2 | (A) Time dependent ThT fluorescence for the inhibition of $\alpha$-Syn $(10 \mu \mathrm{M})$ in absence (black curve) or presence of 5-molar excess of inhibitors, $\mathbf{M}$ (red curve), $\mathbf{N}$ (blue curve), (M+N) (magenta curve), MCN (cyan curve), M2N (gray curve), and $\mathbf{M} 3 \mathbf{N}$ (green curve). (B) The end point ThT fluorescence represented as \% amyloid remaining in the solution of $\alpha$-Syn in absence or presence of different doses of the inhibitors. (C) CD spectra of $\alpha$-Syn in absence (black curve) or presence of different doses of the inhibitors. CD Spectra were recorded after $50 \mathrm{~h}$ of incubation of $\alpha$-Syn in the absence or presence of different doses of inhibitor molecules. All the experiments were performed in PBS $(\mathrm{pH} 7.4,100 \mathrm{mM})$ at $37^{\circ} \mathrm{C}$.

mixed with the inhibitors at various molar ratios $(\alpha-S y n$ : inhibitors $=5: 1,1: 1$, and 1:5). (Figures 2A,B, Figure S9).

The results reveled that $\alpha$-Syn $(10 \mu \mathrm{M})$ alone aggregates and forms fibrils after $30 \mathrm{~h}$ of incubation in $\mathrm{PBS}$ at $37^{\circ} \mathrm{C}$ as evident by the enhanced ThT fluorescence intensity with time (black curve, Figure 2A, Figure S9). All inhibitors significantly inhibited fibril formation of $\alpha$-Syn in a dose dependent manner with greatest reduction of fluorescence intensity, indicating maximum inhibition of fibrillization of $\alpha$-Syn, at 5-fold molar excess concentration of the various inhibitors (Figure 2A). However, even at 5-fold molar excess, Mannitol (M) could only inhibit aggregation by $\sim 17 \%$ (red, Figure $2 \mathbf{B}$ ), indicating that higher doses of Mannitol may be required for achieving substantial reduction of aggregation. This was in accordance with a previous report which found that to inhibit $\sim 90 \%$ aggregation more than 2,000-fold molar excess of Mannitol was required (Shaltiel-Karyo et al., 2013). NQTrp (N, blue, Figure 2B) and the mixture of $\mathbf{M}+\mathbf{N}$ (magenta, Figure 2B) inhibited $\alpha$-Syn aggregation more efficiently than $\mathbf{M}$ (Figure 2B), yet inhibition by the mixture $(\mathbf{M}+\mathbf{N})$ was considerably more profound than NQTrp alone (73 vs. $68 \%$ inhibition with $1: 5$ molar ratio, respectively) at all molar ratios tested, suggesting a synergistic effect of Mannitol and NQTrp. When examining the effect of the three conjugates (MCN, M2N, M3N) on $\alpha$-Syn aggregation it was evident that all of them display a dose dependent inhibition (cyan, gray, green respectively in Figure 2B). Interestingly, among the three conjugates, compound $\mathbf{M} 3 \mathbf{N}$ showed the highest degree of inhibition $(\sim 79 \%)$ close to, and slightly higher than, the effect of the $\mathbf{M}+\mathbf{N}$ mixture ( $\sim 73 \%)$. This indicates that compound $\mathbf{M} 3 \mathbf{N}$ retains the combined inhibitory property of compound $\mathbf{M}$ and $\mathbf{N}$. Compound $\mathbf{M} 3 \mathrm{~N}$ reduced the extent of fibril formation as well as increased the lag time, which makes it more efficient among all the inhibitors tested. We speculate that the longer PEG in M3N than in MCN or M2N might confer upon its greater flexibility required for efficient inhibition than the other two conjugates where the shorter linker may be more rigid than required for efficient interaction with $\alpha$-Syn.

\section{Conformational Transition of Inhibited $\alpha-$ Syn}

The conformational transition of $\alpha$-Syn in absence or presence of different doses of the various inhibitors was measured by Circular Dichroism (CD) at the end-point of fibril formation (Figure 2C, Figure S10). In the CD analysis $\alpha$-Syn alone showed a negative band $\sim 218 \mathrm{~nm}$ and a positive band $\sim 198 \mathrm{~nm}$, which were indicative of $\beta$-sheet rich conformation present in the fibrillar solution (black curve, Figure 2C, Figure S10) as reported (Shaltiel-Karyo et al., 2013). In the presence of various doses of Mannitol (M), the intensity of negative band at $\sim 218 \mathrm{~nm}$ was slightly reduced (Figure S10A and red curve, Figure 2C), which indicates that 5 -fold molar excess may not be high enough to reduce the $\beta$-sheet content of $\alpha$-Syn significantly. In presence $\mathbf{N}$ (blue curve, Figure 2C), the $\beta$-sheet content of $\alpha$-Syn was reduced in a dose dependent manner evidenced from the substantial reduction of CD intensity at $218 \mathrm{~nm}$ with increasing doses of N (Figure S10B). Likewise, a dose dependent effect was observed for the mixture $(\mathbf{M}+\mathbf{N})$ and all three conjugate molecules (MCN, M2N, and M3N, Figures S10D-F).

\section{Morphology of Inhibited $\alpha$-Syn Assemblies}

Morphology of $\alpha$-Syn assemblies in absence and presence of the inhibitors was examined at the end-point of the fibrillization kinetics by transmission electron microscopy (TEM) (Figure 3A, Figure S11A). Since the ThT and CD analyses indicated that at 5:1 molar ratio of $\alpha$-Syn:inhibitors there was hardly reduction of the fibrillization, TEM analysis was performed with 1:1 and 1:5 molar ratio. Assemblies of $\alpha$-Syn alone appeared as dense fibrillar aggregates (Figure 3A) as reported (Scherzer-Attali et al., 2012). At equimolar ratio (1:1) doses of the inhibitors $\mathbf{M}, \mathbf{N}$, $(\mathbf{M}+\mathbf{N})$, and $\mathbf{M C N}$, the fibrillar aggregates of $\alpha$-Syn remained visible, indicating that the dose was not high enough to reduce the level of aggregates significantly (Figure S11). However, the conjugate inhibitors $\mathbf{M} 2 \mathbf{N}$ and $\mathbf{M} 3 \mathbf{N}$ at equimolar markedly reduced the fibrillar assemblies (Figures S11vi,vii). In presence of 5-fold molar excess of $\mathbf{N},(\mathbf{M}+\mathbf{N}), \mathbf{M} 2 \mathbf{N}$, and $\mathbf{M} 3 \mathbf{N}$, the 

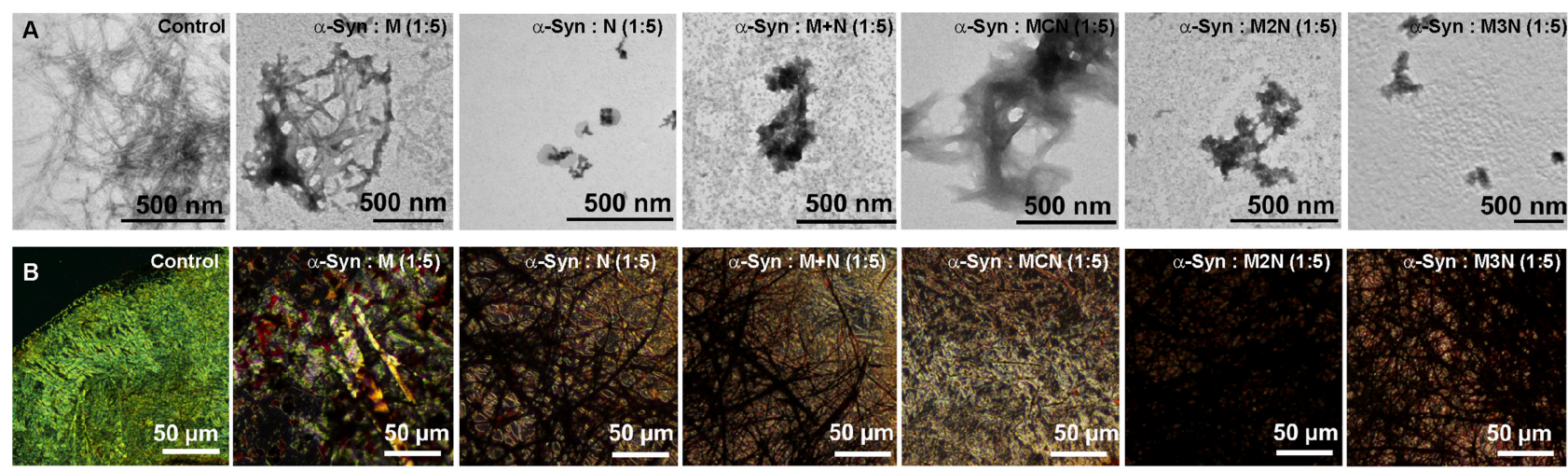

FIGURE 3 | (A) TEM images and (B) Congo red stained birefringence images of $\alpha$-Syn $(10 \mu M)$ in absence and presence of 1:5 molar ratio ( $\alpha$-Syn: inhibitor) of the inhibitor molecules. Images were captured after $50 \mathrm{~h}$ of incubation of $\alpha$-Syn in absence and presence of the inhibitor molecules in PBS $(\mathrm{pH} 7.4)$ at $37^{\circ} \mathrm{C}$.

density of fibrillar assemblies was significantly reduced. However, a mixture of amorphous and fibrils was observed in presence of 5 -fold molar excess of inhibitor MCN (Figure 3A), and no reduction of fibrils was observed in presence 5 -fold molar excess of Mannitol (M), which supports the ThT results (Figure 3A).

\section{Congo Red Birefringence of Inhibited $\alpha$-Syn Assemblies}

Congo red is known as an amyloid specific dye and exhibits yellow green birefringence upon binding with ordered amyloid structures under cross polarized light (Westermark et al., 1999). We used it to further validate the effect of the inhibitors on $\alpha$-Syn fibrillization. Following incubation of $\alpha$-Syn $(10 \mu \mathrm{M})$ in the absence of inhibitors for $50 \mathrm{~h}$ Cong red staining resulted in a clear green-gold or apple-green birefringence, indicating the presence of amyloid fibrils in the sample (Figure 3B, Figure S11Bi). Some green-gold birefringence was observed in $\alpha$-Syn samples that were incubated with 1:1 molar ratio of the inhibitors, indicating that 1:1 molar ratio was not sufficient for inhibition of $\alpha$-Syn fibrillar aggregates, except compound M2N and M3N (Figure S11B) which were more effective, as observed in morphological analysis by TEM. In contrast, no birefringence was observed when $\alpha$-Syn was treated with 1:5 molar ratio of all inhibitors tested except in presence of Mannitol (M) (Figure 3B). Collectively, the results of ThT, CD, TEM, and Congo red birefringence, indicate that the conjugate molecule M3N was a superior among all tested molecules.

\section{Effect of the Inhibitors on $\alpha$-Syn Cytotoxicity}

$\alpha$-Syn assemblies are believed to exert their neurotoxicity in PD by damaging the cell membrane (Winner et al., 2011; Xin et al., 2015; Ghiglieri et al., 2018). To evaluate whether the tested molecules can reduce toxicity of $\alpha$-Syn oligomers and fibrils, we employed two complementary assays, one involving Large Unilamellar Vesicles (LUVs) and the other involving cultured neuronal cells. Monitoring the extent of leakage of Carboxyfluorescein dye from LUVs loaded with it is a commonly used proxy for damage to cell membrane and cytotoxicity by amyloids only or is this a general assay for membrane leakage (Zhu et al., 2003; Williams et al., 2010; Fecchio et al., 2013).

Prior to the leakage assay, the formation of LUVs was confirmed by TEM imaging and they were found to be $\sim 200 \mathrm{~nm}$ in diameter with a characteristic spherical morphology (Figure S12). As a reference Carboxyfluorescein leakage from dye loaded LUVs treated with $10 \%$ Triton X-100, was consider as $100 \%$. Leakage value was calculated from the following equation (McLaurin and Chakrabartty, 1996):

$\%$ dye leakage $=\frac{\text { Fluorescence }_{\text {observed }}-\text { Fluorescence }_{\text {initial }}}{\text { Fluorescence }_{\text {total }}-\text { Fluorescence }_{\text {initial }}} \times 100$

Based on that, spontaneous dye release from the untreated LUVs was calculated as $8 \%$ (yellow curve, Figure 4). For the control experiment, in absence of inhibitors, $\alpha$-Syn oligomers or fibrils were generated by incubating $\alpha$-Syn monomers for 25 or $50 \mathrm{~h}$ respectively (based on the ThT results in Figure 2A). Incubation of $\alpha$-Syn oligomers in absence of inhibitors with the dye-loaded LUVs, resulted in high leakage reaching $\sim 46 \%$ after $600 \mathrm{~min}$ (purple curve, Figure 4). In contrast, mature $\alpha$-Syn fibrils caused only $16 \%$ of dye leakage (black curve, Figure 4 ). For evaluating the effect of the inhibitors on $\alpha$-Syn induced LUV leakage, $\alpha$ Syn monomers were incubated with 5-fold molar excess of the inhibitor molecules for $50 \mathrm{~h}$, during which both oligomers and fibrils could have been formed. Next, the samples were each mixed with the dye-loaded LUVs and leakage was monitored for $900 \mathrm{~min}$ in $10 \mathrm{~min}$ interval.

The samples of $\alpha$-Syn with the inhibitor molecules caused lower level of leakage in comparison to $\alpha$-Syn oligomers without inhibitors. Least amount of leakage $(\sim 11 \%)$ was observed for the $\alpha$-Syn sample in presence of 1:5 molar ratio of compound M3N (green curve, Figure 4), indicating that the molecule M3N prevented formation of membrane disrupting species of $\alpha$-Syn .

To compare the level of leakage caused by $\alpha$-Syn in the presence of 5 -fold molar excess of $(\mathbf{M}+\mathbf{N})$ and $\mathbf{M} 3 \mathbf{N}$ at different time points, we performed an additional LUV leakage assay by incubating $\alpha$-Syn monomers in absence or presence of these inhibitors for 25 and $50 \mathrm{~h}$ (Figure S13). In 


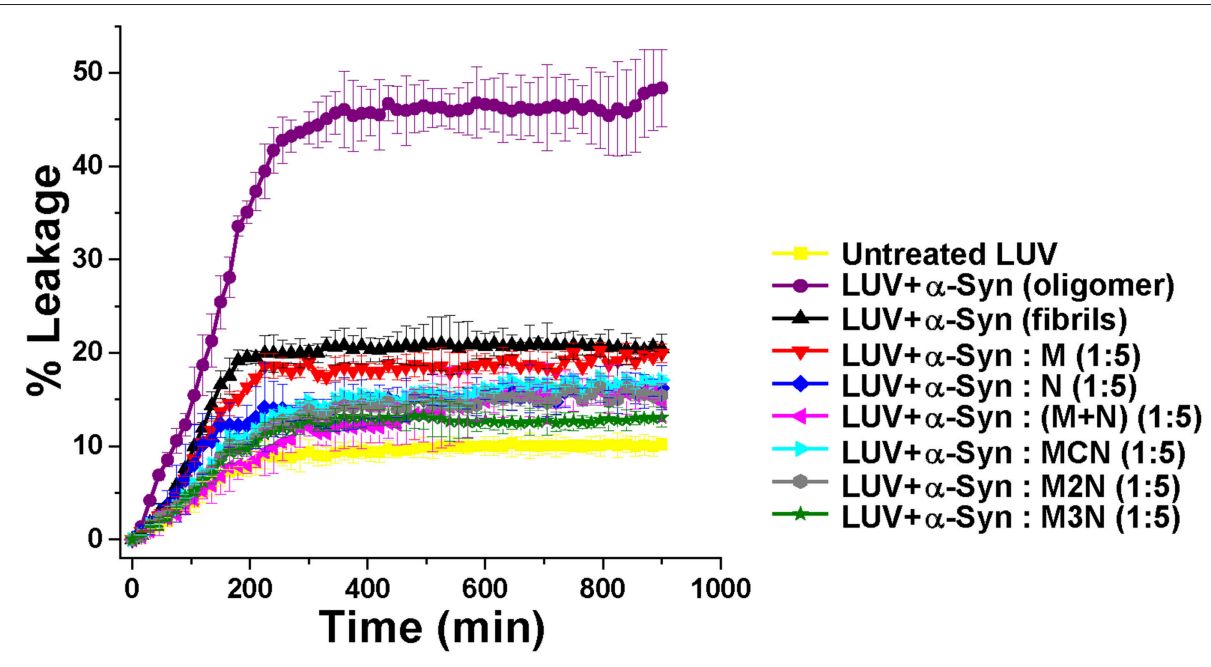

FIGURE 4 | Percentage of dye leakage with time from LUVs treated with $\alpha$-Syn samples in absence or presence of 5-fold molar excess of the inhibitor molecules. The leakage from LUVs treated with Triton X-100 was set as 100\%. Carboxyfluorecein was excited at $490 \mathrm{~nm}$ and emission was recorded at $517 \mathrm{~nm}$.

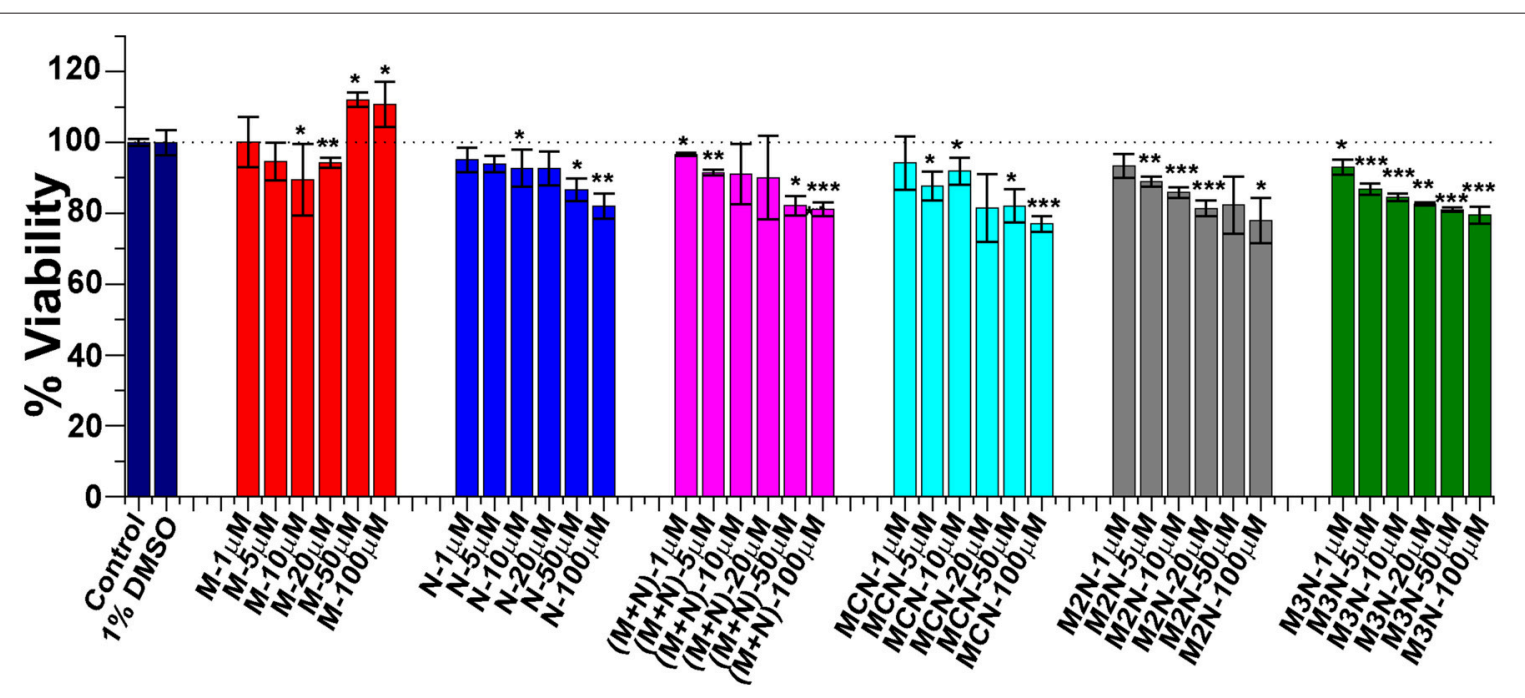

FIGURE 5 | Evaluation of cytotoxicity of the inhibitor molecules toward SH-SY5Y cells. Cells were incubated with the inhibitors at different concentrations (1-100 $\mu$ M) for $24 \mathrm{~h}$ and cytotoxicity was measured by XTT assay. One percent DMSO was used to solubilize the tested compounds (used as vehicle). Untreated cells were used as control and set to $100 \%$ viability. Results are average of 3 independent assays $(n=3-6, \pm S D)$ and are expressed as percentage of control cells. Significance $\left({ }^{\star} p<0.05\right),\left({ }^{\star \star} p<0.005\right)$, and $\left({ }^{\star \star \star} p<0.001\right)$.

the absence of the inhibitors we observed that $25 \mathrm{~h}$ aged $\alpha$ Syn assemblies, which were considered as oligomers, caused higher level of dye leakage $(\sim 43 \%)$ in comparison to mature fibrils (aged $50 \mathrm{~h}$ ) which caused lesser dye leakage $(\sim 16 \%)$ (Figure S13B). In contrast, in the presence of 5-fold molar excess of $(\mathbf{M}+\mathbf{N})$ and $\mathbf{M} 3 \mathbf{N}$, the $25 \mathrm{~h}$ aged $\alpha$-Syn caused lesser dye leakage $(\sim 19 \%$ and $\sim 14 \%$, respectively) than in their absence $(\sim 43 \%)$. Likewise, for $50 \mathrm{~h}$ aged $\alpha$-Syn (fibrils) 5 -fold molar excess of $(\mathbf{M}+\mathbf{N})$, and $\mathbf{M} 3 \mathbf{N}$ caused lesser dye leakage ( $\sim 13$ and $\sim 10 \%$, respectively) than in their absence $(\sim 16 \%)$ (Figures S13A,B). Combining the results of dye leakage by $\alpha-$ Syn at different incubation times in the absence or presence of these inhibitors, we observed that M3N caused lesser dye leakage at the different time points of $\alpha$-Syn aggregation than $\mathbf{M}+\mathbf{N}$, supporting the conclusion that the conjugate molecule $\mathbf{M} 3 \mathbf{N}$ impeded formation of membrane disrupting species of $\alpha$-Syn.

In preparation for evaluating the effect of the various inhibitors on $\alpha$-Syn toxicity toward cells, we first examined whether the inhibitors themselves exhibited cytotoxicity. SHSY5Y neuroblastoma cells were incubated with the various inhibitors were incubated at different concentrations for $24 \mathrm{~h}$ and the viability of cells were analyzed by XTT reduction assay (Figure 5). No substantial cytotoxic effects of the inhibitors themselves on these cells was observed, even at the highest concentration of $100 \mu \mathrm{M}$. 

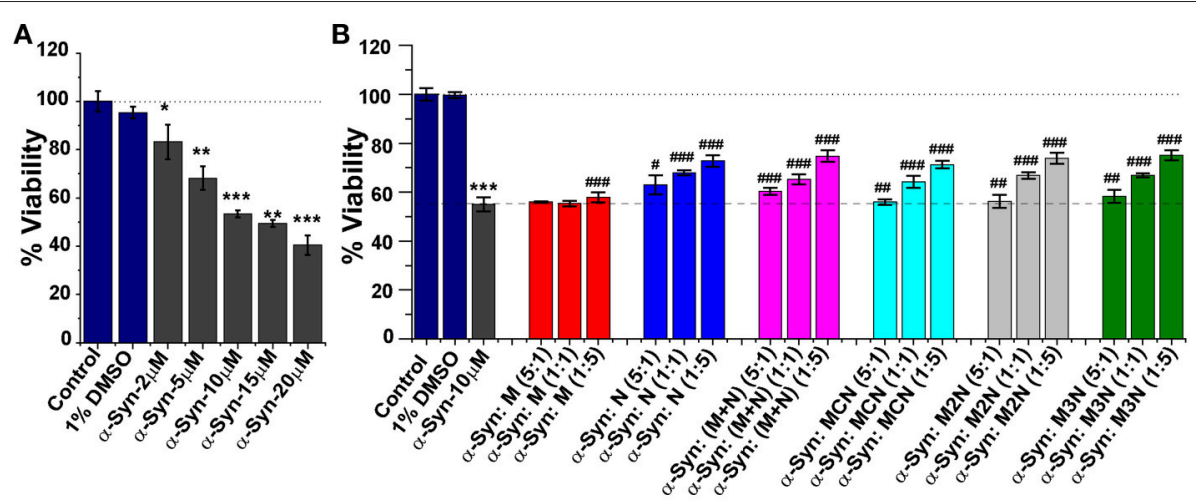

FIGURE 6 | (A) Relative viability of SH-SY5Y cells in presence of different concentrations (2-20 $\mu$ M) of $\alpha$-Syn aggregates measured by XTT assay. (B) Dose-dependent effect of the inhibitor molecules on $\alpha$-Syn mediated cytotoxicity toward SH-SY5Y cells. $\alpha$-Syn (10 $\mu$ M) monomers were incubated in absence or presence of different doses of the inhibitor molecules $(5: 1,1: 1$, and 1:5) for $50 \mathrm{~h}$ and was applied to the SH-SY5Y cells for additional $24 \mathrm{~h}$. Cell viability was measured by XTT assay, Untreated cells were used as control and set to 100\% viability. Results are average of 3 independent assays ( $n=3-6$, \pm SD) and are expressed as percentage of control cells. ${ }^{*} p<0.05,{ }^{* *} p<0.005$, and ${ }^{* \star *} p<0.001$ compared to control group. $\# p<0.05$, \#\#p<0.005, and $\# \# \# p<0.001$ compared to $\alpha$-Syn treated group.

$\alpha$-Syn monomers $(2-20 \mu \mathrm{M})$ were allowed to preaggregate for $50 \mathrm{~h}$. When incubated with SH-SY5Y for $24 \mathrm{~h}$ a dose dependent reduction of viability of the cells was observed with an $\mathrm{IC}_{50}$ value ( $50 \%$ cell death) of $\sim 11 \mu \mathrm{M}$ (Figure 6A). To evaluate the effect of the inhibitor molecules on cytotoxicity induced by $\alpha$ Syn aggregates induced cytotoxicity, $\alpha$-Syn $(10 \mu \mathrm{M})$ was allowed to aggregate for $50 \mathrm{~h}$ in the absence or presence of various molar ratios $(\alpha$-Syn : inhibitor $=5: 1,1: 1,1: 5)$ of the inhibitors. Next, these samples were incubated with the cells for additional $24 \mathrm{~h}$ followed by XTT viability assay.

As shown in Figure 6B, the inhibitor molecules significantly attenuated the cytotoxic effect of $\alpha$-Syn aggregates in a dose dependent manner evidenced as increase of cell viability. At lower dose [0.2 molar excess (5:1)] none of the inhibitors could increase cell viability. Significant increment in viability was observed with increased doses of the inhibitors. For example, at 5-fold molar excess of the inhibitors, compound $\mathbf{N}$ increased cell viability up to $73 \%$, $(\mathbf{M}+\mathbf{N}) 75 \%$, MCN $72 \%$, M2N $73 \%$, and $\mathbf{M} 3 \mathbf{N} 75 \%$. Mannitol (M) had a marginal effect on $\alpha$-Syn induced cytotoxicity, which agrees with the ThT, TEM, and LUV results.

\section{CONCLUSIONS}

Our systematic study of the aggregation $\alpha$-Syn and its inhibition by the Mannitol-NQTrp based conjugate molecules revealed that all the tested molecules including the controls ( $\mathbf{M}, \mathbf{N}$, and $\mathbf{M}+\mathbf{N}$ ) efficiently slowed down the aggregation kinetics of $\alpha$ Syn in a dose dependent manner. Mannitol (M) was the least effective among the tested molecules as evident both from ThT, $\mathrm{CD}$, and TEM assays and this was reflected in its low effect on $\alpha$-Syn cytotoxicity. NQTrp (N) was more effective, yet the mixture $(\mathbf{M}+\mathbf{N})$ displayed higher efficiency than $\mathbf{N}$, indicating synergistic effect of Mannitol and NQTrp. Among the novel conjugate molecules compound, $\mathbf{M} 3 \mathbf{N}$ was the most effective in delaying the process of fibrillization as well as most significantly reduced the $\beta$-sheet content and the extent of fibrils formed. The highest efficacy of $\mathbf{M} 3 \mathbf{N}$ was also manifested in its strongest ability to attenuate membrane disruption by $\alpha$-Syn. M3N was not significantly better in preventing cytotoxicity of $\alpha$-Syn aggregates than $\mathbf{N}$ or $\mathbf{M}+\mathbf{N}$ Conjugate $\mathbf{M} 3 \mathbf{N}$ appears to have similar or better capabilities as $(\mathbf{M}+\mathbf{N})$ mixture, indicating that by employing a longer linker it retained the beneficial attributes of both Mannitol and NQTrp. Since M3N also has low cytotoxicity by itself, it can be attractive as a potential scaffold for development of therapeutic molecules for PD.

\section{AUTHOR CONTRIBUTIONS}

AP, Y-ML, and DS conceived the project. AP performed all the experiments and analyzed the data. B-DZ synthesized all the designed molecules. SM performed Congo red birefringence assay. GL characterized all the molecules synthesized. AP and DS wrote the manuscript with the help of Y-ML and EG. All authors read and approved the manuscript.

\section{FUNDING}

This research was supported by a grant from XIN collaborative fund of Tsinghua University and Tel Aviv University (to DS and Y-ML).

\section{ACKNOWLEDGMENTS}

Authors are grateful to the members of Y-ML, EG, and DS research groups for fruitful discussions.

\section{SUPPLEMENTARY MATERIAL}

The Supplementary Material for this article can be found online at: https://www.frontiersin.org/articles/10.3389/fmolb. 2019.00016/full\#supplementary-material 


\section{REFERENCES}

Ardah, M. T., Paleologou, K. E., Lv, G., Abul Khair, S. B., Kazim, A. S., Minhas, S. T., et al. (2014). Structure activity relationship of phenolic acid inhibitors of $\alpha$-Synuclein fibril formation and toxicity. Front. Aging Neurosci. 6:197. doi: 10.3389/fnagi.2014.00197

Begley, D. J. (2004). Delivery of therapeutic agents to the central nervous system: the problems and the possibilities. Pharmacol. Ther. 104, 29-45. doi: 10.1016/j.pharmthera.2004.08.001

Bendor, J. T., Logan, T. P., and Edwards, R. H. (2013). The function of $\alpha$-synuclein. Neuron 79, 1044-1066. doi: 10.1016/j.neuron.2013.09.004

Bieschke, J., Russ, J., Friedrich, R. P., Ehrnhoefer, D. E., Wobst, H., Neugebauer, $K$., et al. (2010). EGCG remodels mature $\alpha$-synuclein and amyloid- $\beta$ fibrils and reduces cellular toxicity. Proc. Natl. Acad. Sci. U.S.A. 107, 7710-7715. doi: 10.1073/pnas.0910723107

Bisaglia, M., Tosatto, L., Munari, F., Tessari, I., de Laureto, P. P., Mammi, S., et al. (2010). Dopamine quinones interact with $\alpha$-synuclein to form unstructured adducts. Biochem. Biophys. Res. Commun. 394, 424-428. doi: $10.1016 /$ j.bbrc.2010.03.044

Bridi, J. C., and Hirth, F. (2018). Mechanisms of $\alpha$-synuclein induced synaptopathy in Parkinson's disease. Front. Neurosci. 12:80. doi: 10.3389/fnins.2018.00080

Butler, D. C., Joshi, S. N., Genst, E., De Baghel, A. S., Dobson, C. M., and Messer, A. (2016). Bifunctional anti-non-amyloid component $\alpha$-Synuclein nanobodies are protective in situ. PLoS ONE 11:e0165964. doi: 10.1371/journal.pone.0165964

Chiti, F., and Dobson, C. M. (2006). Protein misfolding, functional amyloid, and human disease. Annu. Rev. Biochem. 75, 333-366. doi: 10.1146/annurev.biochem.75.101304.123901

Choi, M. G., Kim, M. J., Kim, D. G., Yu, R., Jang, Y. N., and Oh, W. J. (2018). Sequestration of synaptic proteins by $\alpha$-synuclein aggregates leading to neurotoxicity is inhibited by small peptide. PLOS ONE 13:e0195339. doi: 10.1371/journal.pone.0195339

Choi, M. Y., Kim, Y. S., Lim, D., Kang, S. J., Kim, Y. H., Lee, K., et al. (2011). The hexapeptide PGVTAV suppresses neurotoxicity of human $\alpha$-synuclein aggregates. Biochem. Biophys. Res. Commun. 408, 334-338. doi: 10.1016/j.bbrc.2011.04.034

Conway, K. A., Lee, S. J., Rochet, J. C., Ding, T. T., Williamson, R. E., and Lansbury, P. T. (2000). Acceleration of oligomerization, not fibrillization, is a shared property of both $\alpha$-synuclein mutations linked to early-onset Parkinson's disease: implications for pathogenesis and therapy. Proc. Natl. Acad. Sci. U.S.A. 97, 571-576. doi: 10.1073/pnas.97.2.571

Cookson, M. R. (2005). The biochemistry of Parkinson's disease. Annu. Rev. Biochem. 74, 29-52. doi: 10.1146/annurev.biochem.74.082803.133400

Dauer, W., and Przedborski, S. (2003). Parkinson's disease: mechanisms and models. Neuron 39, 889-909. doi: 10.1016/S0896-6273(03)00568-3

Dedmon, M. M., Christodoulou, J., Wilson, M. R., and Dobson, C. M. (2005). Heat shock protein 70 inhibits $\alpha$-synuclein fibril formation via preferential binding to prefibrillar species. J. Biol. Chem. 280, 14733-14740. doi: $10.1074 /$ jbc.M413024200

Dettmer, U. (2018). Rationally designed variants of $\alpha$-synuclein iluminate its in vivo structural properties in health and disease. Front. Neurosci. 12:623. doi: $10.3389 /$ fnins.2018.00623

Fecchio, C., De Franceschi, G., Relini, A., Greggio, E., Dalla Serra, M., Bubacco, L., et al. (2013). $\alpha$-Synuclein oligomers induced by docosahexaenoic acid affect membrane integrity. PLoS ONE 8:e82732. doi: 10.1371/journal.pone.0082732

Finkelstein, D. I., Billings, J. L., Adlard, P. A., Ayton, S., Sedjahtera, A., Masters, C. L., et al. (2017). The novel compound PBT434 prevents iron mediated neurodegeneration and alpha-synuclein toxicity in multiple models of Parkinson's disease. Acta Neuropathol. Commun. 5:53. doi: 10.1186/s40478-017-0456-2

Frenkel-Pinter, M., Tal, S., Scherzer-Attali, R., Abu-Hussien, M., Alyagor, I., Eisenbaum, T., et al. (2016). Naphthoquinone-tryptophan hybrid inhibits aggregation of the tau-derived peptide PHF6 and reduces neurotoxicity. J. Alzheimers. Dis. 51, 165-178. doi: 10.3233/JAD-150927

Gabathuler, R. (2010). Approaches to transport therapeutic drugs across the blood-brain barrier to treat brain diseases. Neurobiol. Dis. 37, 48-57. doi: 10.1016/j.nbd.2009.07.028

Gazit, E. (2002). A possible role for p-stacking in the self-assembly of amyloid fibrils. FASEB J. 16, 77-83. doi: 10.1096/fj.01-0442hyp
Ghiglieri, V., Calabrese, V., and Calabresi, P. (2018). $\alpha$-synuclein: from early synaptic dysfunction to neurodegeneration. Front. Neurol. 9:295. doi: $10.3389 /$ fneur.2018.00295

Ghosh, D., Singh, P. K., Sahay, S., Jha, N. N., Jacob, R. S., Sen, S., et al. (2015). Structure based aggregation studies reveal the presence of helix-rich intermediate during $\alpha$-synuclein aggregation. Sci. Rep. 5:9228. doi: $10.1038 /$ srep 09228

Glabe, C. G. (2006). Common mechanisms of amyloid oligomer pathogenesis in degenerative disease. Neurobiol. Aging 27, 570-575. doi: 10.1016/j.neurobiolaging.2005.04.017

Harris, J. M., and Chess, R. B. (2003). Effect of pegylation on pharmaceuticals. Nat. Rev. Drug Discov. 2, 214-221. doi: 10.1038/nrd1033

Iljina, M., Hong, L., Horrocks, M. H., Ludtmann, M. H., Choi, M. L., Hughes, C. D., et al. (2017). Nanobodies raised against monomeric als. hogenesis in degenerative disease. ediate during $\alpha$-synuclein aggregation. BMC Biol. 15:57. doi: 10.1186/s12915-017-0390-6

Knowles, T. P. J., Vendruscolo, M., and Dobson, C. M. (2014). The amyloid state and its association with protein misfolding diseases. Nat. Rev. Mol. Cell Biol. 15, 384-396. doi: 10.1038/nrm3810

Kobayashi, M., Kim, J., Kobayashi, N., Han, S., Nakamura, C., Ikebukuro, K., et al. (2006). Pyrroloquinoline quinone (PQQ) prevents fibril formation of $\alpha$-synuclein. Biochem. Biophys. Res. Commun. 349, 1139-1144. doi: 10.1016/j.bbrc.2006.08.144

Leitao, A., Bhumkar, A., Hunter, D., Gambin, Y., Sierecki, E., Leitao, A., et al. (2018). Unveiling a selective mechanism for the inhibition of $\alpha$-synuclein aggregation by $\beta$-synuclein. Int. J. Mol. Sci. 19:334. doi: 10.3390/ijms19020334

LeVine, H. (1999). Quantification of $\beta$-sheet amyloid fibril structures with thioflavin T. Methods Enzymol. 309, 274-284. doi: 10.1016/S0076-6879(99)09020-5

Madine, J., Doig, A. J., and Middleton, D. A. (2008). Design of an N-methylated peptide inhibitor of $\alpha$-synuclein aggregation guided by solid-state NMR. J. Am. Chem. Soc. 130, 7873-7881. doi: 10.1021/ja075356q

Masuda, M., Suzuki, N., Taniguchi, S., Oikawa, T., Nonaka, T., Iwatsubo, T., et al. (2006). Small molecule inhibitors of $\alpha$-synuclein filament assembly. Biochemistry 45, 6085-6094. doi: 10.1021/bi0600749

McLaurin, J., and Chakrabartty, A. (1996). Membrane disruption by alzheimer $\beta$ amyloid peptides mediated through specific binding to either phospholipids or gangliosides. Implications for neurotoxicity. J. Biol. Chem. 271, 26482-26489. doi: $10.1074 / j b c .271 .43 .26482$

Meng, X., Munishkina, L. A., Fink, A. L., and Uversky, V. N. (2010). Effects of various flavonoids on the $\alpha$-synuclein fibrillation process. Parkinsons. Dis. 2010:650794. doi: 10.4061/2010/650794

Milowska, K., Malachowska, M., and Gabryelak, T. (2011). PAMAM G4 dendrimers affect the aggregation of $\alpha$-synuclein. Int. J. Biol. Macromol. 48, 742-746. doi: 10.1016/j.ijbiomac.2011.02.021

Mizuno, N., Varkey, J., Kegulian, N. C., Hegde, B. G., Cheng, N., Langen, R., et al. (2012). Remodeling of lipid vesicles into cylindrical micelles by $\alpha$-synuclein in an extended $\alpha$-helical conformation. J. Biol. Chem. 287, 29301-29311. doi: 10.1074/jbc.M112.365817

Mounsey, R. B., and Teismann, P. (2012). Chelators in the treatment of iron accumulation in Parkinson's Disease. Int. J. Cell Biol. 2012:983245. doi: 10.1155/2012/983245

Pan, G. Y., Liu, X. D., and Liu, G. Q. (2000). Intracarotid infusion of hypertonic mannitol changes permeability of blood-brain barrier to methotrexate in rats. Acta Pharmacol. Sin. 21, 613-616.

Peterson, K. E., Cinelli, M. A., Morrell, A. E., Mehta, A., Dexheimer, T. S., Agama, K., et al. (2011). Alcohol-, diol-, and carbohydratesubstituted indenoisoquinolines as topoisomerase I inhibitors: investigating the relationships involving stereochemistry, hydrogen bonding, and biological activity. J. Med. Chem. 54, 4937-4953. doi: 10.1021/jm101338z

Prabhudesai, S., Sinha, S., Attar, A., Kotagiri, A., Fitzmaurice, A. G., Lakshmanan, R., et al. (2012). A novel \& quot; molecular tweezer \& quot; inhibitor of $\alpha$ synuclein neurotoxicity in vitro and in vivo. Neurotherapeutics 9, 464-476. doi: 10.1007/s13311-012-0105-1

Pujols, J., Peña-Díaz, S., Lázaro, D. F., Peccati, F., Pinheiro, F., González, D., et al. (2018). Small molecule inhibits $\alpha$-synuclein aggregation, disrupts amyloid fibrils, and prevents degeneration of dopaminergic neurons. Proc. Natl. Acad. Sci. U.S.A. 115, 10481-10486. doi: 10.1073/pnas.1804198115 
Ross, C. A., and Poirier, M. A. (2004). Protein aggregation and neurodegenerative disease. Nat. Med. 10, S10-S17. doi: 10.1038/nm1066

Rostovtsev, V. V., Green, L. G., Fokin, V. V., and Sharpless, K. B. (2002). A stepwise huisgen cycloaddition process: copper(I)-catalyzed regioselective "ligation" of azides and terminal alkynes. Angew. Chemie Int. Ed. 41, 2596-2599. doi: 10. 1002/1521-3773(20020715)41:14<2596::AID-ANIE2596>3.0.CO;2-4

Scherzer-Attali, R., Pellarin, R., Convertino, M., Frydman-Marom, A., Egoz-Matia, N., Peled, S., et al. (2010). Complete phenotypic recovery of an Alzheimer's disease model by a quinone-tryptophan hybrid aggregation inhibitor. PLoS ONE 5:e11101. doi: 10.1371/journal.pone.0011101

Scherzer-Attali, R., Shaltiel-Karyo, R., Adalist, Y. H., Segal, D., and Gazit, E. (2012). Generic inhibition of amyloidogenic proteins by two naphthoquinonetryptophan hybrid molecules. Proteins 80, 1962-1973. doi: 10.1002/prot.24080

Shaltiel-Karyo, R., Frenkel-Pinter, M., Egoz-Matia, N., Frydman-Marom, A., Shalev, D. E., Segal, D., et al. (2010). Inhibiting $\alpha$-synuclein oligomerization by stable cell-penetrating $\beta$-synuclein fragments recovers phenotype of Parkinson's disease model flies. PLoS ONE 5:e13863. doi: 10.1371/journal.pone.0013863

Shaltiel-Karyo, R., Frenkel-Pinter, M., Rockenstein, E., Patrick, C., Levy-Sakin, M., Schiller, A., et al. (2013). A blood-brain barrier (BBB) disrupter is also a potent $\alpha$-synuclein $(\alpha$-syn) aggregation inhibitor: a novel dual mechanism of mannitol for the treatment of Parkinson disease (PD). J. Biol. Chem. 288, 17579-17588. doi: 10.1074/jbc.M112.434787

Shrestha-Dawadi, P. B., Bittner, S., Fridkin, M., and Rahimipour, S. (1996). On the synthesis of naphthoquinonyl heterocyclic amino acids. Synthesis 1996, 1468-1472. doi: 10.1055/s-1996-4417

Singh, P. K., Kotia, V., Ghosh, D., Mohite, G. M., Kumar, A., and Maji, S. K. (2013). Curcumin modulates $\alpha$-synuclein aggregation and toxicity. ACS Chem. Neurosci. 4, 393-407. doi: 10.1021/cn3001203

Spillantini, M. G., Schmidt, M. L., Lee, V. M.-Y., Trojanowski, J. Q., Jakes, R., and Goedert, M. (1997). $\alpha$-synuclein in Lewy bodies. Nature 388, 839-840. doi: $10.1038 / 42166$

Stefani, M. (2004). Protein misfolding and aggregation: new examples in medicine and biology of the dark side of the protein world. Biochim. Biophys. Acta 1739, 5-25. doi: 10.1016/j.bbadis.2004.08.004

Suzuki, J., Imaizumi, S., Kayama, T., and Yoshimoto, T. (1985). Chemiluminescence in hypoxic brain-the second report: cerebral protective effect of mannitol, vitamin E and glucocorticoid. Stroke 16, 695-700. doi: 10.1161/01.STR.16.4.695

Tornøe, C. W., Christensen, C., and Meldal, M. (2002). Peptidotriazoles on solid phase: [1,2,3]-triazoles by regiospecific copper(i)-catalyzed 1,3-dipolar cycloadditions of terminal alkynes to azides. J. Org. Chem. 67, 3057-3064. doi: $10.1021 /$ jo011148j

Traïkia, M., Warschawski, D. E., Recouvreur, M., Cartaud, J., and Devaux, P. F. (2000). Formation of unilamellar vesicles by repetitive freeze-thaw cycles: characterization by electron microscopy and 31 P-nuclear magnetic resonance. Eur. Biophys. J. 29, 184-195. doi: 10.1007/s002490000077
Treusch, S., Cyr, D. M., and Lindquist, S. (2009). Amyloid deposits: protection against toxic protein species? Cell Cycle 8, 1668-1674. doi: 10.4161/cc.8.11.8503

Wang, C., Zhao, C., Li, D., Tian, Z., Lai, Y., Diao, J., et al. (2016). Versatile structures of $\alpha$-synuclein. Front. Mol. Neurosci. 9:48. doi: $10.3389 /$ fnmol.2016.00048

Werle, M., and Bernkop-Schnürch, A. (2006). Strategies to improve plasma half life time of peptide and protein drugs. Amino Acids 30, 351-367. doi: 10.1007/s00726-005-0289-3

Westermark, G. T., Johnson, K. H., and Westermark, P. (1999). Staining methods for identification of amyloid in tissue. Methods Enzymol. 309, 3-25. doi: 10.1016/S0076-6879(99)09003-5

Williams, J. K., Yang, X., Atieh, T. B., Olson, M. P., Khare, S. D., and Baum, J. (2018). Multi-pronged interactions underlie inhibition of $\alpha$-synuclein aggregation by $\beta$-synuclein. J. Mol. Biol. 430, 2360-2371. doi: 10.1016/j.jmb.2018.05.024

Williams, T. L., Day, I. J., and Serpell, L. C. (2010). The effect of Alzheimer's A $\beta$ aggregation state on the permeation of biomimetic lipid vesicles. Langmuir 26, 17260-17268. doi: 10.1021/la101581g

Winner, B., Jappelli, R., Maji, S. K., Desplats, P. A., Boyer, L., Aigner, S., et al. (2011). In vivo demonstration that $\alpha$-synuclein oligomers are toxic. Proc. Natl. Acad. Sci. U.S.A. 108, 4194-4199. doi: 10.1073/pnas.1100976108

Xin, W., Emadi, S., Williams, S., Liu, Q., Schulz, P., He, P., et al. (2015). Toxic oligomeric $\alpha$-synuclein variants present in human Parkinson's disease brains are differentially generated in mammalian cell models. Biomolecules 5 , 1634-1651. doi: 10.3390/biom5031634

Zhang, H., Xu, L.-Q., and Perrett, S. (2011). Studying the effects of chaperones on amyloid fibril formation. Methods 53, 285-294. doi: 10.1016/j.ymeth.2010.11.009

Zhu, M., Li, J., and Fink, A. L. (2003). The association of $\alpha$-synuclein with membranes affects bilayer structure, stability, and fibril formation. J. Biol. Chem. 278, 40186-40197. doi: 10.1074/jbc.M305326200

Zhu, M., Rajamani, S., Kaylor, J., Han, S., Zhou, F., and Fink, A. L. (2004). The flavonoid baicalein inhibits fibrillation of alpha-synuclein and disaggregates existing fibrils. J. Biol. Chem. 279, 26846-26857. doi: 10.1074/jbc.M4031 29200

Conflict of Interest Statement: The authors declare that the research was conducted in the absence of any commercial or financial relationships that could be construed as a potential conflict of interest.

Copyright (C) 2019 Paul, Zhang, Mohapatra, Li, Li, Gazit and Segal. This is an open-access article distributed under the terms of the Creative Commons Attribution License (CC BY). The use, distribution or reproduction in other forums is permitted, provided the original author(s) and the copyright owner(s) are credited and that the original publication in this journal is cited, in accordance with accepted academic practice. No use, distribution or reproduction is permitted which does not comply with these terms. 